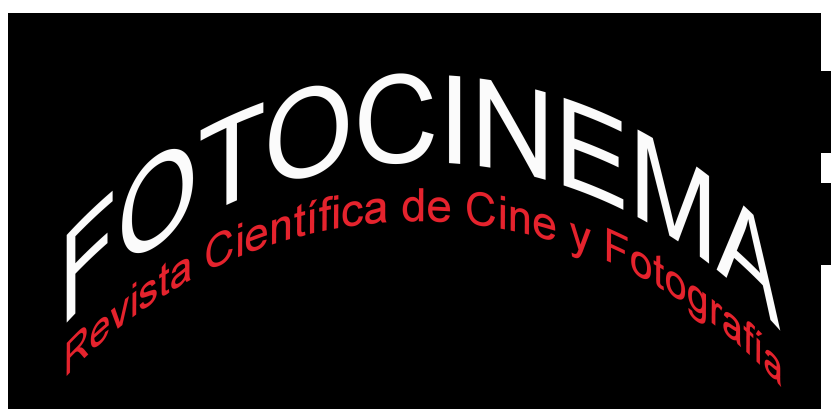

\title{
CINE, VIDEOCLIP AMERICANO Y VIDEOCLIP JAPONÉS: LA DIRECCIÓN DE ARTE COMO HILO CONDUCTOR. EL CASO DE NOT ANOTHER TEEN MOVIE
}

\section{FILM, AMERICAN AND JAPANESE MUSIC VIDEO: THE ART DIRECTION AS COMMON THREAD. THE CASE OF NOT ANOTHER TEEN MOVIE}

\author{
Francisco Vegas Molina \\ Universidad de Málaga \\ crowf6@gmail.com
}

\begin{abstract}
Resumen:
La relación entre cine y videoclip es una cuestión estudiada por los adeptos tanto de una como de otra parte de la ecuación. Estas relaciones suelen abarcar el sentido técnico de ambas materias en tanto que una se nutre de la otra (o la otra de la una); el sentido narrativo donde en ocasiones entra en juego también el propio teatro; el cultural de por qué estas interferencias que con frecuencia ocurren en el ámbito técnico se producen; y, cómo no, el estético.

Sin embargo, se va a dar por sentada de antemano la relación entre el cine y el videoclip en todos estos sentidos al coger como caso un clip que, con motivos promocionales, se ha extraído a conciencia de una película. Este es, el caso del videoclip Tainted Love (2002), protagonizado por Marilyn Manson y dirigido por Phillip G. Atwell, y de la película No es otra estúpida película americana (Not another teen movie, Joel Gallen, 2001). De esta forma, el análisis se focalizará en cómo todos estos "puentes" (técnico, cultural, visual, narrativo) entre uno y otro terminan condensándose al servicio de la imagen y el simbolismo, para volverse a repetir con un motivo meramente artístico $^{1}$ por un tercer actor promocional: el grupo de visual kei japonés The Gazette, con la canción que da nombre a su videoclip Inside Beast (Toshihiko Imai, 2013).
\end{abstract}

\begin{abstract}
:
The relationship between film and video is a matter studied by adherents of both one and the other part of the equation. These relationships tend to cover the technical sense of both subjects while a thrives on the other (or another one); the narrative sense that sometimes enters the game also the theater itself; cultural sense of why these interferences that often occur in the technical field are produced; and, of course, aesthetic sense, also closely linked to the latter, among others.

However, it is taken for granted in advance the relationship between film and video in all these respects to take as a clip case, for promotional purposes, has been extracted from a film confirmed conscience. This is the case of the video Tainted Love (2002), starring Marilyn Manson and directed by Phillip G. Atwell, and film Not Another Teen Movie (Not Another Teen Movie, Joel Gallen, 2001) which is extracts the first. Thus, the analysis will focus on how all these "bridges" (technical, cultural, visual, narrative) between the two end up condensing the service image and symbolism, to go to repeat with a purely artistic motif for Promotional third foreign actor visual kei group The Gazette, with the title track to his video Inside Beast (Toshihiko Imai, 2013).
\end{abstract}

\section{Palabras clave:}

cine; videoclip; dirección de arte; visual kei; publicidad

Keywords:

Cinema; Videoclip; Art Direction; Visual Kei; Advertising

1. Se hace referencia a un motivo meramente artístico en tanto que este tercer actor ha necesitado una referencia cultural para comunicar un determinado mensaje, no en el sentido de que esta acción no se haya producido por fines económicos o promocionales. 


\section{Introducción}

La dirección de arte audiovisual, más que como una disciplina al uso, puede dibujarse como un medio capaz de vincular tres elementos de una disparidad considerable: una película americana, un videoclip occidental y un videoclip oriental. Salvando el intrínseco parentesco técnico, funcional y profesional, esta disparidad vendría representada además de por la propia singularidad de las piezas, por estar situadas en dos décadas diferentes, en dos países culturalmente opuestos y por ser, además, realizadas por directores distintos. Es por ello que encontrar ciertas similitudes radicales mediante el seguimiento del simbolismo, intereses y marcos culturales en los que se encuentra cada uno de los elementos no hace si no justicia al hecho mismo de identificar la triquiñuela entre líneas que se hace con el mérito de tal hazaña.

Esta, a priori, escurridiza relación pude al menos hacer acto de presencia si se visualizan las tres obras de forma consecutiva, por lo que es el aspecto visual el punto de partida más correcto para indagar. Aspectos como colorimetría, vestuario y atrezzo (entre otros) son el compendio que reclama el término "aspecto visual", y su consecución a conciencia lo que se denomina dirección artística, por lo que es el núcleo sobre el que girará el análisis planteado.

\section{Marco teórico}

En base a este núcleo, encontramos como pieza fundamental el análisis del término realizado en Dirección de arte en publicidad por Mahon (2010) donde se muestra esta disciplina desde el punto de vista tanto teórico como práctico, algo bastante adecuado si tenemos en cuenta que el análisis visual que se llevará a cabo se hará sobre aspectos que presenten una disponibilidad desde el resultado visual más que de la propia planificación de los mismos. En base a los establecidos por el propio autor y a los ofrecidos por las piezas audiovisuales, se atenderá a describirlos con la mayor exactitud posible. Así pues, la forma de relación principal y su funcionamiento entre cine- 
videoclip-videoclip oriental quedará respaldada por un acercamiento adecuado.

No obstante, y para comprender la relación entre estos elementos, deben entenderse los pilares fundamentales sobre los que se asientan. El primero se sitúa no en el cine o el videoclip como tal, si no en la propia dicotomía cinevideoclip, para lo cual el trabajo de García Gómez (2009) El hijo marchoso del cine: relaciones e interdependencias entre el cine y el videoclip, se hace idóneo por plantear el estudio de la interdependencia entre ambos factores más que como una relación "causa-efecto" como una inevitable relación de parentescos y similitudes que no terminan en uno con el comienzo del siguiente, si no que se mantienen, vuelven, desaparecen o incluso se omiten durante años, estilos y opiniones, lo cual plantea un enfoque acertado para dar por hecho la relación técnica y conceptual entre ambos elementos.

Este punto de vista va siempre ligado a lo que el autor denomina la estética videoclipera, la cual no solo puede darse propiamente en el videoclip, sino también en el cine (y no precisamente de forma reciente); es una estética que a su vez se caracteriza por no únicamente cuestiones visuales al uso, si no también técnicas, referentes a realización, efectos...etc, por lo que es un concepto que cubre las necesidades de comprender cómo se unen ambos formatos, además de, en una segunda línea, la forma en que una relación (la visual) está entrelazada con otra de diferente tipo (la técnica).

Además, García Gómez sienta como uno de los principios de este concepto los fines comerciales sujetos al marketing y a la promoción, un punto de partida que, sin duda, une en sus cimientos la relación entre los elementos a analizar, en la medida en que el videoclip de Tainted Love es una acción promocional de la película No es otra estúpida película americana y/o viceversa ${ }^{2}$.

2. A pesar de que Tainted Love comenzó a grabarse el 21 de abril de 2001 y se finalizó tres días después, no fue hasta 2002 cuando se produjo su lanzamiento. Si se tiene en cuenta que No es otra estúpida película americana fue estrenada el 14 de diciembre de 2002, se puede apreciar que el letargo del videoclip lo hizo al menos coincidir con el período inicial de campaña de la película. 
Dejando a un lado la relación cine-videoclip y, por tanto, No es otra estúpida película americana-Tainted Love, se ha hecho pertinente encontrar un enfoque centrado en el cine como actor cultural y capaz de transmitir creencias a nivel internacional, estableciendo así un primer nivel de relación entre No es otra estúpida película americana-Inside Beast. Es por eso que, salvando (tal vez en menor medida de lo que a priori pudiera parecer) las distancias entre los mensajes que estudia, Cruz Roldán (2009) en Evolución de la imagen del enemigo de Estados Unidos en el cine norteamericano durante el siglo XX: estereotipo nazi, comunista $e$ islamista hace un excelente repaso por la capacidad del séptimo arte para crear estereotipos, creencias y valores, sin dejarlos en el etéreo de esta afirmación, si no situándolos en fines tan palpables como la propaganda militar. Esta capacidad descrita por el autor proyecta la silueta que también reflejan otros mecanismos simbólicos, como los producidos por EEUU durante la época de los 80 y 90 en el ámbito juvenil y adolescente.

Sin embargo, para que estos sean transportados de EEUU a Japón, deben pasar por el embudo condensador propio del videoclip y de aquella estética denominada videoclipera por lo que volver a una segunda línea relacional entre cine-videoclip vuelve a hacerse pertinente en este caso para la dimensión referente a "contenedor" de símbolos. En un esfuerzo por comprender cómo un concepto puede ser reducido a sus más básicas facciones y aun así seguir siendo el mismo, Paraíso (1997) en Teoría psicoanalítica de la caricatura arroja luz en cuanto al carácter comunicativo y estético de lo irreductible. Sin embargo, no es suficiente ver como los conceptos viajan, si no también cómo llegan. Es por eso que un acercamiento al marco cultural del país nipón y, más allá, al género musical dentro del cual arraigan los símbolos americanos para su puesta en escena en Inside Beast es pieza clave para cerrar los puntos fuertes a investigar en este proceso. Para ello, en primer lugar, Fortea (2012) en Reconfigurando el género, la estética y la "japonesidad": el visual kei como alternativa a las dicotomías sancionadoras masculino/femenino y japonés/no japonés nos introduce en el escenario estético y artístico desde el cual se toman estos mensajes visuales. En segundo lugar, Vegas (2015) La dirección de arte en el visual kei 
japonés acerca el propio uso de la disciplina por el género musical en cuestión.

Finalmente y, para matizar algunas de las cuestiones que puedan surgir por conflicto entre la dirección de arte planificada y la ejecutada, así como de la propia materia junto a otras en una obra audiovisual, el trabajo de García Crespo y Ramahí (2013): El reto tecnológico en la gestión de los procesos productivos cinematográficos ofrece información específica sobre la interrelación de las diferentes disciplinas que tienen su sustento en el marco tecnológico en referencia a la consecución de una película.

\section{Metodología}

Dado que este estudio sopesa variables de un origen ciertamente subjetivo, como son apreciaciones visuales o contextos culturales, se ha optado por un corte cualitativo en su desempeño.

Nos situamos ante un análisis de contenido en su versión cualitativa sobre el que se pretende arrojar luz mediante un estudio de documentos visuales, así como de diferentes variables que se estudiarán de forma paralela en los mismos, respectivamente. Desde esta propuesta se ha escogido una muestra que incluye los soportes mencionados: la producción de No es otra estúpida película americana (2001) y los videoclips Tainted Love (2002) e Inside Beast (2013). En todos ellos se abordarán categorías relacionadas con la dirección artística, atendiendo a parámetros de la misma que puedan darse en los tres soportes sin perderse sobremanera en las particularidades de cada uno; estos son: colorimetría, vestuario y caracterización, encuadre e iluminación de personajes y escena, entre otras puntualizaciones referentes a la postproducción y al propio contexto y/o contextos sobre los que se desarrollan los metrajes.

No obstante, no sólo es la pertinencia el único criterio global sobre el que se plantea registrar estos parámetros. Cabe destacar en este punto la reflexión que Vernallis (2015, p. 1) plantea ante la problemática de analizar un videoclip, en tanto que por sus características se prestan sobremanera a ser estudiados, pero, por las mismas, no se encuentra un arquetipo estándar de 
análisis: "Music videos lend themselves to analysis. They're rich, evocative, and short. Repeated viewings can bring new aspects of them to light. But there aren't many analytical models to draw upon. Scholarship on the genre is underdeveloped”. Es por eso que la autora parte de algo tan simple como preguntarse “¿por qué me gusta este vídeo?” para desarrollar una pequeña lista de necesidades de información que extraer de la pieza. Un proceso similar y, rescatando a su vez algunos de estos parámetros citados por Vernallis, contribuirá a construir el criterio atendido para seleccionar elementos de las muestras.

Así pues, esta simple pregunta escapa a la trivialidad cuando entendemos, explica la autora, que esa pequeña huella que queda tras ver una pieza audiovisual no es si no el resultado de la repetición de una serie de secciones muy marcadas presentes tanto en videos musicales como en largometrajes, resultado de los medios que los mismos emplean para sus fines:

Music videos, like feature films, use many devices to achieve their ends, and leave other techniques aside. Since each video leans on certain techniques and it's the chorus that draws me in, I might begin by asking whether the video breaks into strongly demarcated song-sections. To follow this further I might ask-how much does this video highlight song sections?(Lyric sheets and tablature transcriptions can be useful for determining sections even when a student doesn't have musical training.) Often, especially in classic, commercial music videos, visual and song sections parallel one another (2015, p. 2).

¿Cómo se marcan, pues, estas secciones? Evidentemente, en cada video los recursos son particularmente intrínsecos al mensaje del mismo. No obstante, y en base a los criterios usados por la autora en el caso, podemos deducir que hay patrones más generales: "How do color and texture help convey the video's music and story?” (p. 3) es un criterio del que podemos deducir la colorimetría y sus variaciones según el desarrollo del metraje como uno de los agentes centrales. "How do the figures move and where are they placed in the frame?” (p. 5) sitúa las pautas de realización en función de la imagen como una variable bastante importante. "How might costumes help during underscore the music and convey the story?" (p. 13) aborda un aspecto 
primordial de la dirección artística como es el vestuario para sacarlo como pauta a seguir.

Como se puede observar, estas pautas no solo pueden darse en un videoclip, si no también en un largometraje, por lo que podemos efectuar unos criterios de análisis convenientemente transportables a uno y otro formato si elegimos: color, escena, personajes y caracterización como criterios generales aplicables al análisis de los tres documentos.

\section{De la película occidental al videoclip oriental}

\subsection{La película}

No es otra estúpida película americana es una comedia producida por Columbia Pictures que aglutina una serie de estereotipos de las numerosas películas americanas de la época, poniéndolos en una constante apropiación de aquellos guiones que le dieran vida tiempo atrás, siempre desde la hipérbole propia de la parodia. Así, encontramos personajes que se autopresentan según su propio estereotipo: el chico popular, el rubio odioso, la chica fea bonita, el obeso idiota, la chica extranjera que siempre está desnuda, etc.

Dicha estereotipación desmesurada no es sino una caricatura de estos roles cinematográficos, si se entiende desde el propio significado etimológico de esta palabra, como apunta Paraíso (1997, p. 98): "los 'ritratti carichi' (retratos cargados, sobrecargados) suponen una transformación deliberada y rebajante en los rasgos de una persona”. Esta autora, además, recalca el “carácter social, de comunicación” de esta forma de expresión, indicando además que: "al igual que las demás formas cómicas, la caricatura implica, en el artista, un descubrimiento involuntario de alguna fealdad esencial, y en el receptor un conocimiento intelectual” (p. 102).

Por tanto, la caricatura está concebida para comunicar mediante una transformación. En este caso, esta transformación se produce sobre las aptitudes del personaje, exagerándolas, simplificándolas y mostrándolas sin más intríngulis al espectador, el cual las percibe con tal facilidad que incluso 
siente una cierta "satisfacción” por ser parte de ese acto comunicativo. No obstante, esta "sencillez perceptiva” no podría producirse sin un adecuado apoyo visual, es decir, sin una caricatura también sobre los elementos de la escena que refuercen y muestren el mensaje tal cual se concibe. Este apoyo visual no es más que la dirección de arte de la película, si se toma desde la definición que diera Mahon (2010) como:

término que se emplea para designar el proceso de organización de los elementos visuales de cualquier medio de comunicación, ya sea una película, un programa de televisión, una instalación digital, un anuncio televisivo o impreso (...) [es la] presentación visual del mensaje publicitario. (p. 11).

Por ende, estos personajes no son solo tan caricaturescos por el papel al que dan vida, si no por su propia apariencia, como ocurre en la caricatura al uso. Es por este motivo que, durante el metraje, el vestuario de cada personaje es prácticamente invariable: la chica fea que luego resulta ser guapa va siempre con peto, camiseta, gafas y coleta; el chico popular, con su equipación propia de fútbol americano; el mejor amigo de la chica fea con vestuario de granjero; las chicas populares con su vestido de animadora, la chica mala con un intento fallido de uniforme puritano... y así personaje a personaje.

Todos estos vestuarios están, por supuesto, recogidos de aquellas películas del género de las que No eso otra estúpida película americana se apropia. Por ejemplo, el personaje de Janey Briggs al ser una caricatura del de Laney Boggs de She's all that (Robert Iscove, 1999), lleva estas ya mencionadas gafas, peto vaquero y camiseta. O en el caso de Jake Wyler, principalmente un mix entre Freddie Prinze Jr. de la misma película y James Vander Beeks de Varsity Blues (Brian Robbins, 1999), la chaqueta del equipo escolar es casi su segunda piel. Sin embargo, hay un segundo nivel de apropiación visual más significativo ya que será básicamente el hilo conductor que más se respete entre los tres productos audiovisuales: el color.

Prestando atención a la película se puede apreciar que la colorimetría que predomina es azul cerúleo/ultramar, blanco y distintos tonos de naranjas y rojos, algo que se puede ver en diversos elementos como material escolar, prendas, letreros, las propias taquillas y toda la imagen corporativa del instituto. 


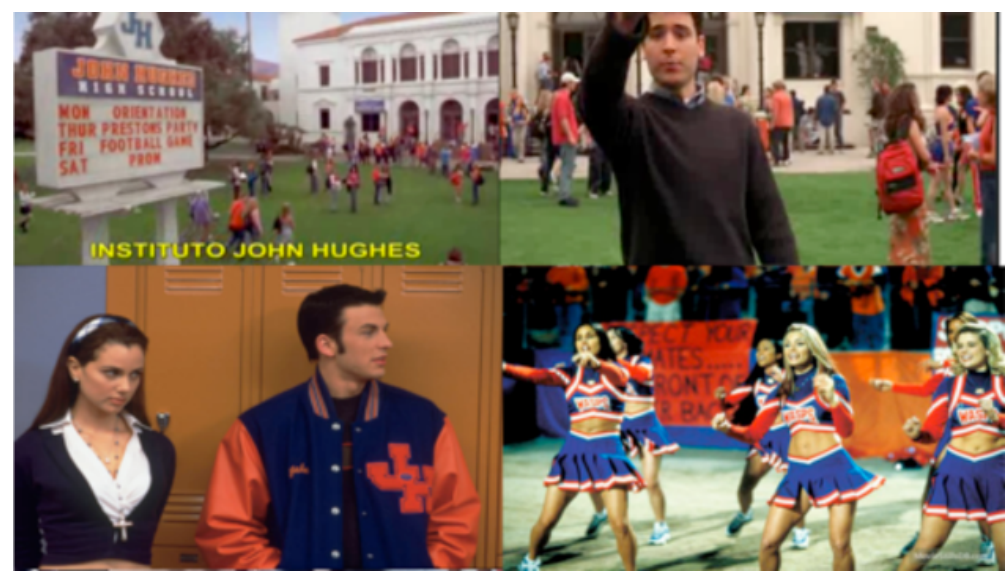

F1: imágenes de No es otra estúpida película americana

Por otro lado, si se atiende ahora a la colorimetría de todas las películas en las que se basa, podrá apreciarse que estos colores son los mismos que caracterizan la dirección artística de las mismas (F2). Entre ellas se encuentran la anteriormente citada Varsity Blues, The Breakfast Club (John Hughes, 1985), American Beauty (Sam Mendes, 1999), Cruel Intentions (Roger Kumble, 1999), Cool, Runnings (John Turteltaub, 1993), Alguien como tú (She's all that) y Nunca me han besado (Never been kissed, Raja Gosnell, 1999) entre otras.

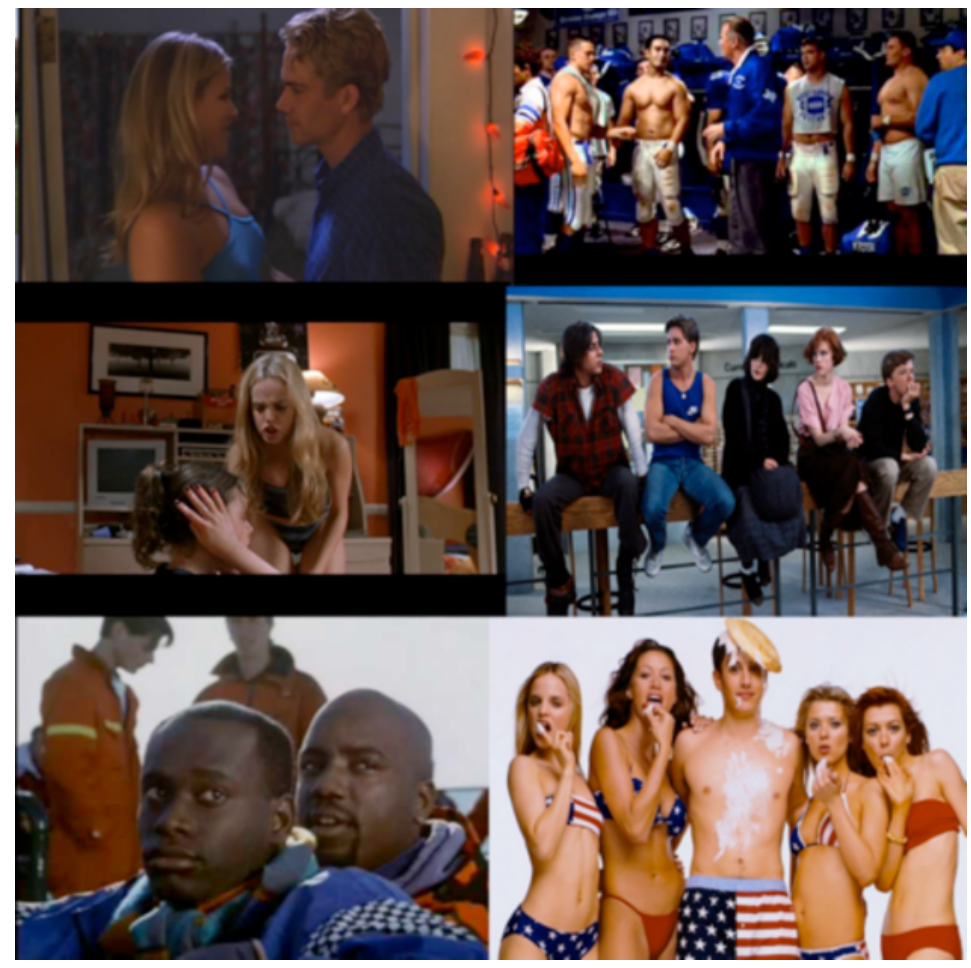

F2: imágenes de las películas que han servido de inspiración 
La paleta vuelve a repetirse. En algunos casos, un naranja más amarillento y un azul más cerúleo, y en otros, un naranja más rojizo y un azul más ultramar. En definitiva, todos estos colores quedan recogidos en todo momento en la película en cuestión. No es pretensión de este artículo ahondar demasiado en el origen simbólico de los mismos, o en el porqué de estas variaciones entre naranjas y azules. No obstante, se puede ver en el efecto en pantalla de estas películas y otras de la época, una especie de warm filtter que hace las pieles más bronceadas, los amarillos más naranjas y los azules más apagados. Por otro lado, recurriendo a las portadas de estas películas y otros materiales publicitarios, los colores (esta vez sin interpretaciones sobre filtros) son puramente azul ultramar, blanco y naranja rojizo/rojo.

Es muy posible que sea en la última de American Pie (F2) donde aparece la clave del porqué de estos colores. Para más seguridad, cabría hacer un pequeño ejercicio de abstracción mental y vislumbrar a un guionista de los 90 que decide hacer una película ambientada en un instituto americano y decide intentar venderla. ¿Por dónde empezaría? ¿Tal vez por "es el típico instituto americano en el que...”? Efectivamente, las palabras claves son "típico" y "americano", y no hay nada más típicamente americano que los colores de la bandera: azul, rojo y blanco. No obstante, si se piensa ahora en la mente de un director artístico, también es fácil caer en el error que sería hacer una película sólo comprendida por rojos y azules. Así que, ¿̇por qué no usar sucedáneos que también categoricen un poco la escena? Por ejemplo, naranjas y azules cerúleos, que además armonizan perfectamente con esos warm filter.

Llegados a este punto, tal vez cabría preguntarse si no es mucha pretensión que un director de arte baraje factores de post-producción para adecuar los colores de la escena. A este respecto, resulta alentadora la reflexión que realizan García Crespo y Ramahí García (2013):

Existe una creencia generalizada y errónea que sitúa la gestión de los efectos visuales como una faceta más de la fase de postproducción, cuando éstos pueden establecer relaciones con los departamentos de desarrollo de vestuario, con cuestiones relativas a la planificación de cámara o con la 
dirección de arte en alguno de sus apartados. Por ello, la producción de efectos visuales debe empezar en las primeras fases del proyecto cinematográfico. (p.61).

Por otro lado, hay que apuntar un factor cultural importante a tener en cuenta. Con el fin de la guerra fría (1989) Estados Unidos se convierte en la potencia mundial, exportando su imagen y símbolos a todo el mundo, como afirma Cruz (2009, p. 21). Para este autor, además, "una gran industria cinematográfica puede ser equiparable a un ministerio en términos de persuasión, sugestión y poder" (p. 6) en base a la idea de Soft Power $^{2}$ por la cual:

un Estado que recurre al Soft Power puede conseguir el apoyo de otros tan solo proyectando una imagen atractiva de sí mismo. De esta manera los Estados observadores que se sienten atraídos o seducidos por los logros, características y/o cualidades de dicho Estado empezarán a actuar de la misma manera adoptando sus comportamientos.

Por tanto, no sería descabellado pensar que fuera una tendencia/casi moda la exportación así como adopción masiva de la simbología estadounidense unida a valores propios de la juventud de la época mediante el cine, entre otros medios.

Así las cosas, la dirección artística de la película está basada, por un lado, en un vestuario muy marcado, característico de cada personaje caricaturizado y, por otro, en una colorimetría anclada en una compilación de las películas del género hasta la época, inspirada en un trasfondo de simbología estadounidense. En otras palabras, los colores de esta película son Norteamérica.

\subsection{El videoclip de la película}

Poco después, en 2002, un ya consolidado y polémico Marilyn Manson lanza su single Tainted Love, una cover de la que hiciera Soft Cell sobre la original escrita por Edd Cobb para la banda The Tour Preps en 1964. Manson da sentido a la denominación single con un videoclip inspirado en No eso otra estúpida película americana, para el cual usa a los actores protagonistas y

2. Término acuñado por Cruz (2009, p.5) y definido como "Poder fundado en influencias intangibles o indirectas como cultura, valores e ideologías". 
secundarios de la película, así como una de las situaciones más típicas en las que estos se puedan encontrar: una fiesta adolescente.

El objetivo del videoclip es recrear una de las típicas fiestas americanas, tal cual se haría en las películas parodiadas, con la excepción de que se incluye a Marilyn Manson en la ecuación, según cuenta el director del clip Phillip G. Atwell en el programa "Making the video"3 emitido por MTV.

La consecución de esta idea se recrea en la típica casa americana de porche blanco, con los protagonistas de la película entrando o ya dentro disfrutando del encuentro y, por supuesto, con todo ambientado y dispuesto como una celebración adolescente de manual. Es en este contexto donde se aprecia como un coche Lincoln Continental de 1969 entra en escena, del cual descienden Marilyn Manson y su séquito goth, poniendo numerosos toques de cuero, excentricidad y desmadre al encuentro. La llegada propicia una serie de cambios en el evento pero también en la protagonista de No eso otra estúpida película americana la cual modifica su vestuario para convertirse en una chica gótica, logrando agradar a Manson en un segundo plano discursivo. En un primero, la chica mala guía a Manson por las escaleras hasta un dormitorio donde se le puede ver con una serie de peluches los cuales, tras cobrar vida, resultan ser chicas ligeras de ropa disfrazadas que comienzan a interactuar con él. Durante toda esta acción, se convierte en verdadera protagonista del videoclip la chica popular, la cual queda enamorada de Marilyn y lo persigue por toda la casa hasta toparse con la habitación donde previamente lo han llevado. La pasional animadora forcejea con el pomo de la puerta para tratar de entrar, pero, cuando lo consigue, Manson ya no está.

En toda esta acción y, como es evidente, hay un cambio considerable en la escena (tanto narrativa como visual) que se produce con la llegada de Marilyn Manson. No obstante, ¿cómo se produce ese cambio? ¿Cómo se pasa de una típica fiesta americana, a una fiesta americana reconvertida por una tribu goth? La respuesta, una vez más, está compuesta de 3 palabras: rojo, blanco y azul. 
No obstante, los 3 componentes se unen de una forma un tanto diferente a como lo hacen en la película, tal vez por estar comprendidos al fin y al cabo dentro de una estética videoclipera4. Esta estética tiene una serie de características definitorias, de las cuales enumera García Gómez (2009, p. 48) como primera la: "preferencia por las imágenes impactantes y dinámicas, por los efectismos. El resultado es una saturación visual, de gran heterogeneidad formal y plagada de referencias icónico-culturales”.

En lo que a "imagen impactante y efectismo" se refiere, el comienzo del videoclip es clave. En los primeros segundos del mismo toda la escena está empapada por una descarada luz azul, otra aún más descarada roja y un fondo predominantemente blanco. Este efecto comienza a interactuar con los atuendos deportivos de los protagonistas (naranjas rojizos, azules y blancos) y otros en los que predomina el azul, además de con el propio Manson y su séquito que se ve mimetizado entre sí llevando pequeños detalles en rojo.

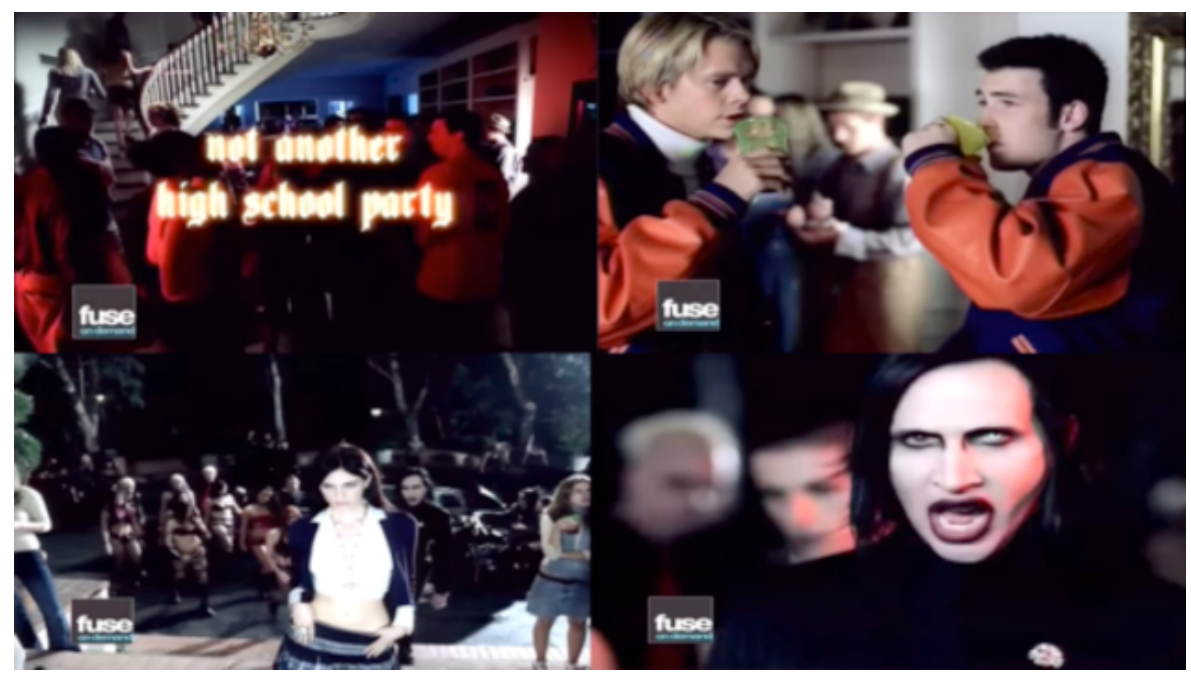

F3: Comienzo de Tainted Love

Con el avance del videoclip, y desde la aparición de Manson, se puede ver cómo la luz roja se atenúa progresivamente, dando paso a colores azules acompañados por una luz violácea, con toques de rojo/naranja que aparecen, ahora sí, exclusivamente en el vestuario, como se puede comprobar en la bailarina o en el invitado especial, el batería de la banda Slipknot.

4 Término acuñado por García Gómez en Historia, estética e iconografía del videoclip musical (2009). 
Es con esto con lo que se podría ejemplificar esa "heterogeneidad formal" que caracteriza la imagen videoclipera, así como las "referencias culturales", las cuales, como ya se ha podido adivinar, apuntan hacia el simbolismo americano en la imagen.

No se debe olvidar, por otro lado, que la dominante violácea comienza a aparecer de forma severa a partir del minuto 1:26, cuando la chica fea que luego se convierte en guapa altera su título para convertirse en una chica de estética gótica. Además, los cosméticos que usa para llevar a cabo tal drástico cambio son de color morado, así como la habitación en la que se encuentra (F4). De forma paralela, en el making of puede verse que en esta escena el efecto de luz morada se consigue mediante un softbox proyectado sobre una cortina del mismo color.

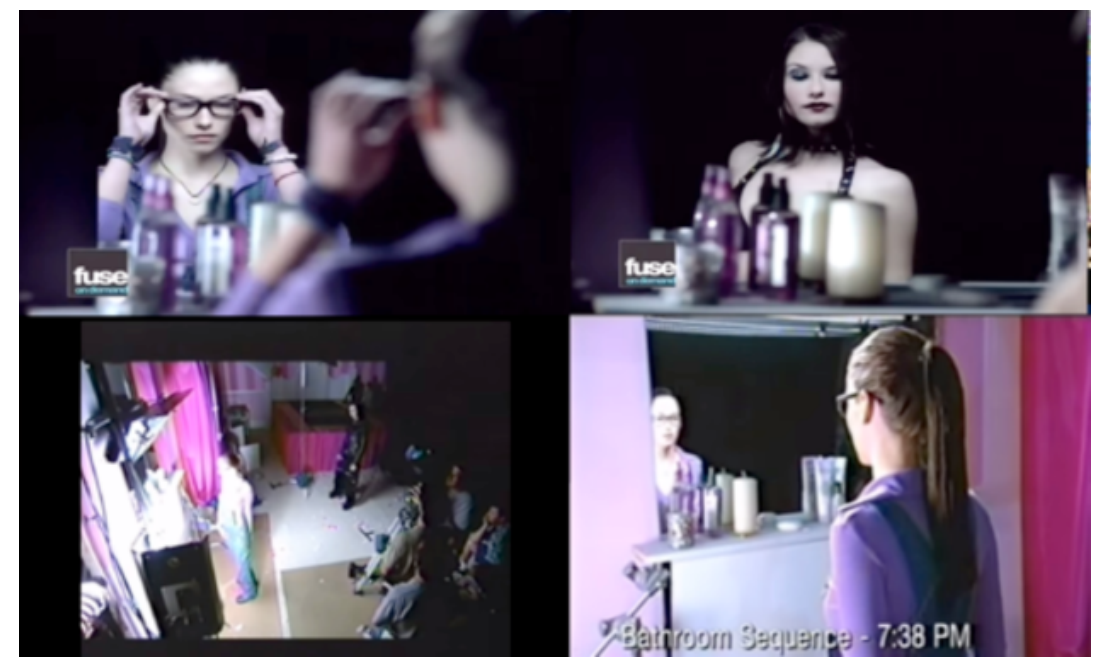

F4: Dominante violácea. Videoclip y Making of

En escenas posteriores y en base a planos más amplios, se observa que el efecto vuelve a ser buscado, esta vez con la propia luz ante la imposibilidad de colocar una monumental cortina del mismo color sin que aparezca en el plano.

También cabe destacar un efecto de postproducción que ayuda a percibir un cambio en la escena con la llegada de Manson. Desde su aparición, se puede observar cómo el marco de la escena va convirtiéndose en un gradiente negro, apagando los blancos, agrisándolos y creando un aura de oscuridad en la imagen. Sobre este efecto se deben advertir una serie de cosas. La primera es que, en un principio, se puede ver sólo cuando Marilyn Manson está en la 
escena (minuto 0:45 y 0:53), de forma mínima, desapareciendo cuando el plano enfoca a otro lugar de la misma estancia segundos después, y reapareciendo cuando de nuevo es Manson el que está siendo filmado. Es decir, es un efecto irreal e inverosímil5 que acentúa el cambio que va a acontecer con la llegada de Marilyn.

La segunda es que este efecto va teniendo variaciones sobre sí mismo, ya que en estos primeros planos se presenta con una oscuridad poco extendida, muy concentrada en los bordes (normalmente solo en un borde y en la zona superior), mientras que en otros es todo lo contrario: crea una especie de región fuera de foco oscura, embruteciendo en cierta medida la escena (minuto 0:19, Marilyn y el batería de la banda Slipknot observando a la streaper). Otra de estas variaciones es que termina por aparecer simplemente en lugares en los que no está físicamente Manson pero sobre los que ha tenido efecto su presencia, como la escena de break-dance (minuto 1:50) o la correspondiente a la chica fea pero guapa al terminar de convertirse frente al tocador $\left(\mathrm{F}_{4}\right)$. De esta forma, a ese efecto violáceo/azulado sobre la imagen y a esos toques de rojo se suma una densa oscuridad que poco a poco aparece con más frecuencia.

Llegados a este punto se hace oportuno plantear la cuestión que atañe a dónde está la protagonista, aquella que recorría la casa con desesperación hasta localizar a Manson en un cuarto lleno de peluches. La realidad es que no ha abandonado su objetivo en ningún momento. De hecho, es la única que sigue conservando de forma total el naranja rojizo, el azul y el blanco en su uniforme, y que irrumpe en la escena continuamente haciendo gala de los mismos. Sigue siendo un nexo de unión con la película, todavía mantiene los colores del género, y además choca tanto con la nueva escenografía que, sin duda alguna, esta chica queda encargada de ir mostrando el verdadero "hilo argumental” de la historia. Algo necesario si se quiere seguir manteniendo un cierto orden que no haga al espectador desprenderse de "qué se está parodiando" o, más bien de "qué parodia se está parodiando", ya que para realizar al completo esa conversión en la imagen se ha necesitado de un dj al

5 La abundancia de efectos reales e inverosímiles es otra de las características de la estética videoclipera, definida por García Gómez (2009, p. 50). 
que apartan de su mesa, un baile que se convierte en pista de break-dance, un jacuzzi, una chica que cambia radicalmente su apariencia en un tocador, una habitación llena de peluches, una barra con streapers.... Es decir, "una gran ubicuidad espacio-temporal, una evidente ruptura de las convenciones narrativas [...] como resultado de la mayor parte de estos recursos" (García Gómez, 2009, p. 50) por lo no está demás un naranja entre tanto color frío.

Todos estos elementos hacen que en el videoclip de Tainted Love se haga una conversión progresiva de la colorimetría y la dirección de arte propias de una película americana convencional y de No es otra estúpida película americana en particular, creando así un nuevo híbrido, una especie de “americanada gótica” compuesta ahora por azules, dominantes violáceas, blancos rotos y puntos de color rojo, de forma que el espectador va percibiendo poco a poco el cambio sin abandonar, con la ayuda además de una protagonista vestida de naranja rojizo, el objeto de conversión.

\subsection{El videoclip del videoclip}

Sin embargo, no es hasta más de una década después, el 23 de octubre de 2013, cuando el grupo de visual kei japonés The Gazette lanzará su álbum "Beautiful Deformity", con la canción Inside Beast como segunda de la lista, así como su correspondiente videoclip.

Antes de describir en detalle este videoclip, hay que tener claras una serie de premisas sobre este recién mencionado visual kei. Por definición, Fortea lo describe como la:

etiqueta que representa una corriente musical y estética que se empezó a cultivar en Japón sobre todo a partir de la década de 1980 y que destapa nuevas alternativas ya no sólo musicales y estéticas, sino también de género e identidad a los valores que imperan en nuestros días. (Fortea, 2012, p. $71)$.

En tanto que estético, este movimiento tiene una característica esencial en cuanto a la imagen en su formato audiovisual según apunta Vegas (2015), y es que "la dirección de arte del visual kei supone una disciplina completamente imprescindible para la significación del propio movimiento”. 
Es decir, la imagen dentro del visual es un modo de expresión situado en el mismo nivel que la propia canción. No obstante, en lo referente al videoclip, esta imagen no es sólo la propia de los integrantes, sino también la de los elementos (atrezzo, escenografía, extras) usados en el PV6 (Vegas, 2015).

Por tanto, impera la premisa de que ninguno de los elementos visuales que encontremos dentro de este videoclip están puestos u organizados de forma meramente aleatoria, en el sentido de que no sólo hace "bonita" la imagen, si no que todo debe transmitir el mismo mensaje que la propia canción y que los integrantes. Por supuesto, con esta afirmación no hay que malinterpretar una dirección artística como una labor que pueda falsearse mostrando elementos al azar de forma igualmente válida sin un mensaje pretendido en ello. Lo que sí hay que entender es que se está haciendo referencia a otro país completamente opuesto al occidental, por lo que sentar firmemente estas afirmaciones ahora deslegitimará cualquier prejuicio que pueda surgir durante la travesía del "mensaje" por el pacífico. Se da por sentado, pues, que los elementos visuales en este movimiento están colocados, ordenados y coreografiados de una forma igual o más minuciosa que los pertenecientes a clips occidentales.

En esta línea, lo primero que se aprecia en el videoclip (independientemente del característico packshot ${ }^{7}$ inicial) es una fiesta en una casa de porche y paredes blancas. Entre planos intercalados se presenta, por un lado, a los miembros de la banda tocando y, por otro, a una limusina acercándose. Esta limusina se detiene en el porche blanco de la casa y de ella desciende el vocalista de la banda, acompañado por dos niñas pequeñas de apariencia tétrica. Estos entran en la fiesta sin pasar desapercibidos y comienzan a recorrer la casa. A la vez, se puede ver al mismo protagonista en una cama con peluches detrás, a los miembros del grupo desempeñando diferentes acciones (una especie de sodomización masoquista, una quema de cartas y otros objetos y un baile con una chica enmascarada) así como planos de los mismos tocando. Tras esta sucesión de escenas, el vocalista consigue llegar al

6 PV (promotional video) son las siglas utilizadas en Japón para denominar al videoclip en los grupos del movimiento.

7 Más información sobre el concepto en Vegas (2015) en La dirección de arte en el visual kei japonés. 
que parece su destino. Abre la puerta y se encuentra en la habitación de los peluches, viendo que su otro “yo” está tumbado en la cama observándolo.

Con esta sobre-desarrollada sinopsis ya se puede advertir la coincidencia de ciertos elementos con los que aparecen en Tainted Love. Así, sin más descripción visual, coinciden:

1. Una fiesta en una casa

2. Un coche oscuro que aparece

3. Un frontman que se baja y entra a la fiesta

4. El mismo frontman que está ya en la casa en una cama con peluches detrás.

Así presentados surge la obviedad de que pueda ser todo una mera similitud aleatoria. Sin embargo, si se van analizando cada uno de estos parecidos de forma visual y con la base de lo que suponen en el universo visual kei, se descubre que lo que en sus traducciones escenográficas puede parecer una coincidencia es más bien una inspiración.

\subsubsection{Una fiesta en una casa}

En el videoclip de Manson la fiesta, como indicaba su director, estaba inspirada en aquella típica que se desarrolla dentro del prototipo de casa americana. ¿Y cómo es esa casa? A ojos del director, blanca y con un porche a la entrada de columnas del mismo color. Si se toman de nuevo las palabras clave, "típico" y "americano", sonará a otro de los símbolos nacionales del país, pero, como no es el caso profundizar sobremanera en ello, se dejarán entendidas como elementos de características objetivamente analizables. Ahora, si se comparan las casas de ambos videoclips, se puede observar que estas idiosincrasias se repiten, con variaciones arquitectónicas obvias de una construcción singular (F5). Además, cuando el coche aparece en escena, la dirección cuida que se sigan apreciando estas columnas en el plano. 


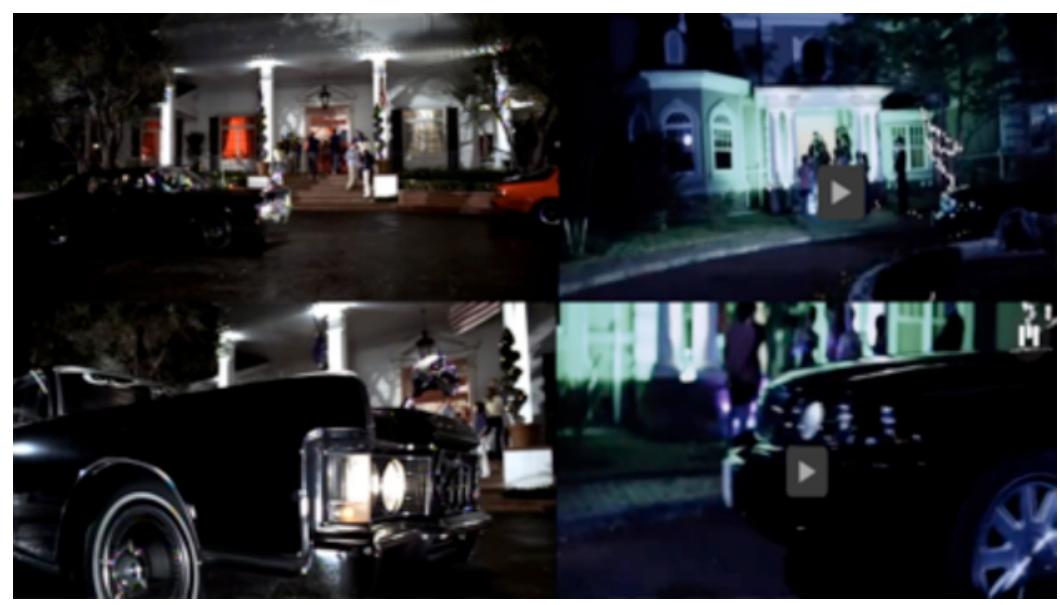

F5: comparativa de fotogramas de "entrada del vehículo" entre los videoclips de Tainted Love (izquierda) e Inside Beast (derecha)

Además, hay una considerable cantidad de planos (nueve, para ser más exactos) introductorios que muestran con ahínco el lugar donde están los invitados (un porche con columnas blancas) más que a los propios invitados en sí. Siempre hay un lugar en el encuadre para que hagan acto de presencia estas columnas. Es más, el propio frontman o el mayordomo están descentrados dentro del plano para hacer sitio a las mismas, o los intérpretes aparecen en algunas ocasiones dando la espalda con toda la normalidad que puede plantear la acción que ejecutan: hablar con otros. Este hecho remarca aún más la intencionalidad del mismo si tenemos en cuenta que "en los PV de visual kei la dirección de arte llega incluso a modificar los tiempos y ritmos de rodaje" (Vegas, 2015).

\subsubsection{Un coche que aparece}

Esta coincidencia tal vez se pueda intuir en el epígrafe anterior, sin embargo, hay otros datos que, vistos al detalle, muestran más matices sobre el elemento en cuestión. Los vehículos sólo se asemejan en que ambos parecen ciertamente lujosos (en Tainted Love por ser un Lincoln Continental y en Inside Beast por ser una limusina) y de color negro. Sin embargo, hay otro dato más curioso que excede la propia apariencia al uso del coche.

En Inside Beast solo un ojo muy experto podría determinar el modelo de coche, el año de lanzamiento, la marca...etc, pero sólo hay que indagar un poco para saber que Japón es uno de los pocos países donde se conduce por la izquierda y donde el asiento del conductor se halla, por tanto, en la 
derecha. Si, no obstante, se presta atención al plano donde se muestra al conductor (minuto o:08) (alguien sin relevancia en todo el vídeo, ya que sólo está curiosamente en este plano) el asiento en el que se encuentra está a la izquierda. Este dato puede pasar desapercibido para el público occidental (en su mayoría), ya que es costumbre ver esta distribución. Sin embargo, para el público japonés, sería tan llamativo como para los demás encontrar el caso contrario.

\subsubsection{Un frontman que se baja del coche}

Justo tras la aparición del vehículo, al igual que en Tainted love, el vocalista del grupo baja del mismo y se adentra en la casa. Esta acción ocurre de forma un tanto particular en cada formato. En Tainted love Manson bajaba seguido de un séquito formado por una tribu goth, así como por los integrantes de su grupo. En Inside Beast, el cantante Ruki desciende seguido por dos gemelas de unos 10 años.

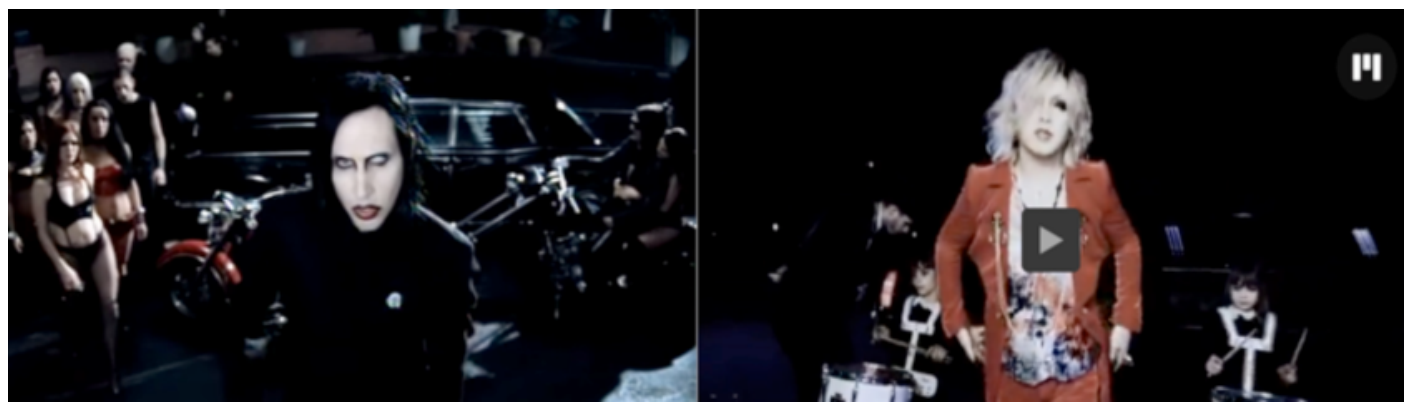

F6: comparativa de fotogramas de "entrada a la fiesta" entre los videoclips de Tainted Love (izquierda) e Inside Beast (derecha)

Este hecho está relacionado con una generalidad que suele ocurrir en los grupos de visual kei y es que parece ser fundamental la separación visual de los músicos dentro del PV, por lo que dotar de una estética visual a los extras del mismo supondría una gran dificultad añadida a la diferenciación, tal y como explica Vegas (2015). En otras palabras, la estética visual está configurada en torno a dar a los integrantes del grupo una autonomía total en la adaptación de su estética siempre y cuando quede claro, dentro del propio clip, quién forma parte del grupo y quién no. Por tanto, usar unos extras como séquito de estética rocambolesca como en Tainted love entorpecería 
apreciar la idiosincrasia del visual kei en el vídeo, así como de cada uno de los integrantes.

Por otro lado, el hecho de que sean niñas es otro de los recursos de estos grupos, ya que pueden fundirse con la escena, pero su edad es algo que desvela su no pertenencia a la banda, por lo que deviene de su uso una función meramente estética, no artística (Vegas, 2015). Por tanto, el séquito de Manson queda perfectamente traducido a las necesidades del movimiento nipón ante una cámara.

\subsubsection{El mismo frontman en una cama con peluches detrás}

Esta similitud tal vez sea una de las más características, ya que la traducción visual es prácticamente literal. En Tainted love la habitación que se sitúa como destino final de la acción y de la protagonista está compuesta por una cama de tonos rosados, con una serie de peluches detrás y con Marilyn Manson de rodillas con un atuendo para dormir oscuro. En Inside Beast, esta descripción es exactamente igual.

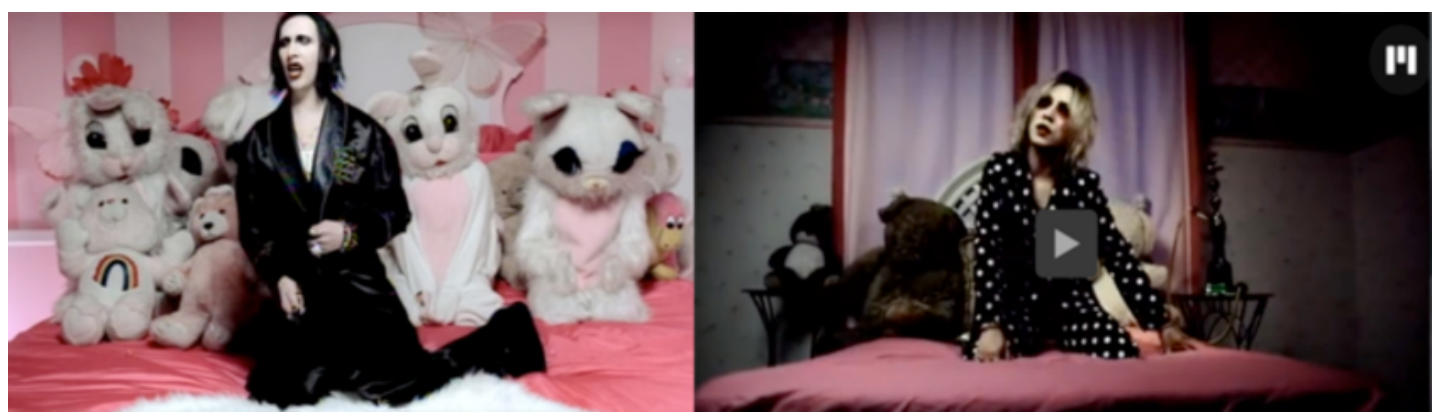

F7: comparativa de fotogramas de "camas con peluches" entre los videoclips de Tainted Love (izquierda) e Inside Beast (derecha)

Y ya que queda de nuevo mencionado el papel del frontman, cabría hacer una profundización en el mismo. En Tainted Love, hay una acción principal: el protagonista llega a la fiesta y es guiado hasta una habitación de peluches, relevándose el protagonismo como tal a la chica popular, la cual recorre la casa hasta encontrar dicha estancia. En Inside Beast, por su parte, estos dos papeles se han fusionado: el protagonista llega a la fiesta, recorre la casa buscando una habitación en concreto hasta que la encuentra, resultando ser la de los peluches con él mismo dentro, sólo que con otro atuendo. Sin embargo, hasta darse ese momento culmen, pasamos por: habitaciones con 
los integrantes del grupo tocando, una escena de sodomización, un baile con una chica enmascarada, una quema de objetos, una carta en llamas, escenas de pasillo, escenas de la fiesta y otras de la cama con peluches. Es decir, se volvería a la misma inverosimilitud narrativa de la que hablamos en el caso anterior.

¿Cómo marcar cual es la acción principal, aquella que comienza con la bajada del coche y acaba en la habitación de los peluches? De la misma forma que con el videoclip anterior, dándole el protagonismo al rojo anaranjado. Así, igual que la chica popular vestía el naranja, el protagonista ahora también, con la consecuente mezcla algo goth que caracteriza su estética. Incluso, muestran cierta similitud en el peinado.

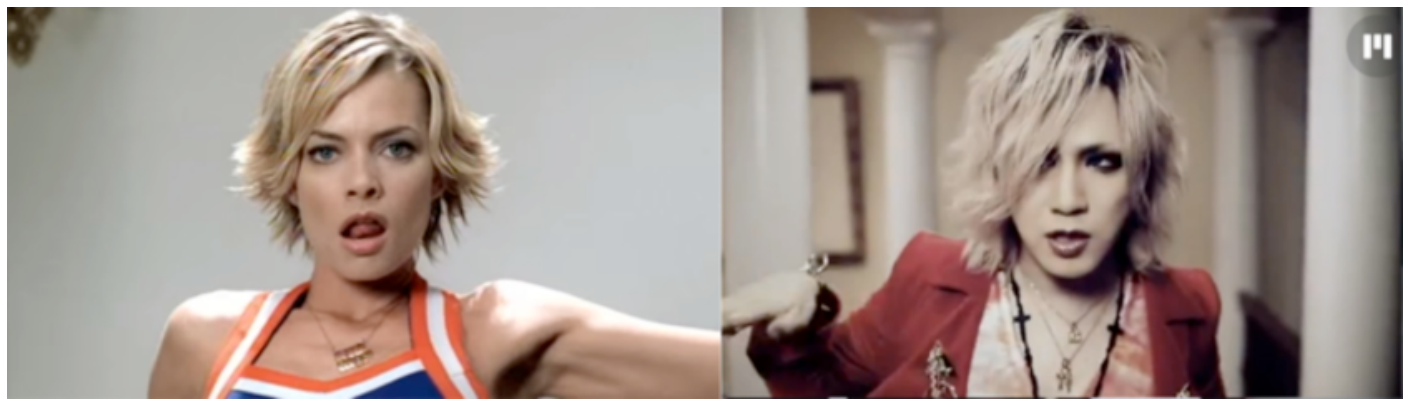

F8: comparativa de protagonistas entre los videoclips de Tainted Love (izquierda) e Inside Beast (derecha)

Sacadas a escena las palabras "mezclas" y "color", tal vez sea momento de llegar al punto fuerte de esta comparativa, siendo este, sin duda, la colorimetría. Como se veía en el ejemplo anterior, el rojo anaranjado, el azul ultramar y el blanco habían hecho una conversión en sus aplicaciones, quedando el rojo anaranjado para puntos del vestuario o de la escena, abandonando así toda procedencia lumínica; el azul ultramar algo mezclado con una luz violácea que lo hacía todo mucho más tétrico y el blanco convertido en un blanco roto manchado por esa misma luz. Esta colorimetría, por su parte, es la que se emplea principalmente en Inside Beast.

El rojo anaranjado ya no viene de ninguna luz, solo aparece en toques del vestuario o elementos de la escena, por lo que todo resulta mucho más frío. Además, solo es perenne en la vestimenta de la protagonista, la cual marca 
una acción principal por contraste con el resto de la escena. No obstante, en Inside Beast sí que se aprecia este rojo, además de en lo mencionado, en algunas paredes de la escena y además con una significativa saturación, sobre todo en aquellas donde están tocando los integrantes del grupo. Este recurso también está bastante extendido en los PV del género, ya que trata de crear contraste mediante la perspectiva cromática como explica Villafañe (1990, p. 97) y recogen Vegas (2015): "los colores forman un bloque indiviso con la superficie, donde hay un contraste de luces pero no formando un gradiente, que es el mecanismo que crea la profundidad”. De esta forma, “el color contribuye a crear una imagen siempre lo más plana y armónica posible, donde la gran mayoría de elementos (en primer o segundo plano) adquieran, además, prácticamente la misma iluminación, a excepción de los rostros cuya sobreexposición es una de las prioridades en la dirección de arte del visual kei” (Vegas, 2015).

El azul se registra principalmente en sombras. La escena está empapada por una luz azul/violácea que lo hace todo mucho más lúgubre. Esta luz, además, viene acompañada al principio por otra verde de igual intensidad, cuyo contraste la hace mucho más espectacular, al igual que ocurría con el desmesurado uso de la luz roja y azul al principio del clip de Tainted love.

El blanco queda con toques de morado, mostrándose apagado, triste y desaliñado. De hecho, si se extrae en uno de los pocos fotogramas de Tainted love donde se aprecia una pared totalmente blanca (minuto 2:07) (habiéndose producido ya esta conversión del color) y se compara con los interiores de pasillo de Inside Beast (1:44), podrá verse que el resultado cromático es el mismo.

Y, ¿qué ocurre con el gradiente negro que aparecía "fortuitamente"? Como el resto de coincidencias, vuelve a aparecer. Donde más significativo se hace es en la escena de la cama con peluches (F7), la cual, por cierto, también coincide con la de Tainted love en ser la única colorimetría rosa de la escena. Otras en las que hace acto de presencia es en las escenas dentro de las habitaciones, las cuales con el paso del protagonista se encuentran acogiendo escenas un tanto grotescas o sencillamente tétricas, algo parecido a los efectos tras el paso de Marilyn o con él in situ. 
De esta forma, queda expuesta que la colorimetría de Inside Beast es, con puntos de adaptación a la estética visual, una apropiación de aquella que bautizáramos de "americanada gótica", la cual no fue sino el híbrido de mezclar el simbolismo cromático americano con el goth.

\section{Conclusiones}

Como ya se anunciaba, el propósito de este estudio es hacer un seguimiento de los símbolos que genera cierto tipo de cine y que, mediante el formato del videoclip y de la dirección artística como principal nexo de unión entre los aspectos visuales de ambos tipos de pieza audiovisual, se traducen y se extienden hacia otras metas. En este caso, se ha comprobado como un videoclip de una corriente japonesa se apropia de la estética manufacturada por un crítico exacerbado de la propaganda política americana como es Marilyn Manson, el cual hace esta apropiación independientemente de por sus ideales, por su propio lucro. Este acto, junto a muchos otros, han hecho siempre de la figura de Manson alguien mítico en el mundo de la moda goth y de la polémica que esta siembra. Si además se tiene en cuenta que el grupo The Gazette tiene una muy notable afiliación con la sub-etiqueta Kote Kote kei8, aquella que se define por la androginia y la oscuridad, resultará evidente que uno de sus grandes referentes no pueda sino ser el mismo Manson.

En otras palabras, mediante la dirección artística, un artista puede hacerse con una fuerte simbología, presentarla bajo su apropiación personal en un formato mucho más publicitario e impactante en tiempo reducido que un largometraje, y hacer de la misma algo fácilmente aprovechable por otros artistas que buscan una fuerte e inmediata vinculación con según qué valores estéticos y/o expresivos. Una afirmación que, por otro lado, y de una forma más manifiesta pero no por ello menos interpretativa, puede respaldarse ante la comparativa de los títulos The golden age of Grotesque, disco de

8 Dentro del movimiento visual kei es común encontrar sub-etiquetas utilizadas desde occidente para categorizar de alguna forma las diferentes formas de expresión de estos artistas. Estas sub-etiquetas, aunque no utilizadas en Japón, demuestran ciertas similitudes entre unas caracterizaciones y otras entre bandas. 
Marilyn Manson que recoge su cover de Tainted love , y Beautiful deformity, nombre con que The Gazette bautiza el álbum donde se encuentra Inside Beast.

La dirección artística se convierte en una herramienta efectiva para aglutinar una serie de estereotipos recogidos de la rama cinematográfica y convertirlos bajo un punto de vista particular en una nueva estética ligada a los mismos públicos y conceptos (juventud, diversión, moda). Por otra parte es capaz de hacerlos llegar a otros sujetos que buscan transmitir exactamente estos mismos valores, así como otros de carácter más personal pertenecientes a la propia expresión artística de los mismos.

En este sentido, la colorimetría juega un papel fundamental en esta transmisión expresiva más allá del atrezzo o el vestuario, repartiéndose a conveniencia entre estos elementos, así como entre los derivados de la dirección de fotografía, la postproducción o las propias localizaciones. El color en la dirección de arte se presenta como símbolo irreductible y adaptable para escenarios culturales diferentes, movimientos artísticos peculiarmente independientes y fines comerciales particulares. En el caso que nos ocupa, se ha comprobado como el rojo, el azul y el blanco, ya sea mediante fuentes de luz o material tangible, en estado puro o bajo filtros, pueden reinventarse a sí mismos sin perder su esencia para encerrar los valores que un día se le dieran y liberarlos a conveniencia de sus diferentes usuarios dejando tras de sí una huella imborrable.

\section{Referencias bibliográficas}

Cruz Roldán, S. (2009). Evolución de la imagen del enemigo de Estados Unidos en el cine norteamericano durante el siglo XX: estereotipo nazi, comunista e islamista. Bogotá D.C: Universidad colegio mayor de nuestra Señora del Rosario.

García Crespo, O., \& Ramahí García, D. (2013). El reto tecnológico en la gestión de los procesos productivos cinematográficos. FOTOCINEMA. Revista Científica de Cine y Fotografía, $\mathrm{N}^{\mathrm{o}} \quad 7, \quad$ pp. $\quad 43-71$ http://www.revistafotocinema.com/index.php?journal=fotocinema\&page $=\mathrm{a}$ rticle\&op=viewFile\&path\%5B\%5D=178\&path\%5B\%5D=116

García Gómez, F. (2009). Historia, estética e iconografía del videoclip música. El hijo marchoso del cine: relaciones e interdependencias entre el cine y el videoclip. Málaga: Universidad de Málaga, pp.43-142. 
Fortea, D. (2012). Re-configurando la estética, el género y la «japonesidad»: el visual kei como alternativa a las dicotomías sancionadoras masculino/femenino y japonés/no japonés. Puertas a la lectura, 14, pp. 7196.

Paraíso, I. (1997). Teoría psicoanalítica de la caricatura. Valladolid: Universidad de Valladolid, pp. 95-104.

Vegas, F. (2015). La dirección de arte en el visual kei japonés. En A. Gómez Gómez y A. Melendo (Eds). Paisajes visuales. Universidad de La Laguna, Tenerife: Sociedad Latina de Comunicación Social.

\section{Bibliografía}

Fandiño Alonso, X. (2003) Introducción a producción publicitaria en medios audiovisuales. Vigo: Universidad de Vigo.

Flores Martínez, M.J.: (2013). La fotografía de moda en el cine: Funky Face y Blow up. FOTOCINEMA. Revista Científica de Cine y Fotografía No 7, pp. 73-98 http:/ $/$ www.revistafotocinema.com/index.php?journal=fotocinema\&page $=\mathrm{a}$ rticle\&op=viewFile\&path\%5B\%5D=182\&path\%5B\%5D=120

Pérez Ríu, C. (2010) El retrato del doble: sobre los lenguajes del cine y el teatro. ARBOR Ciencia, Pensamiento y Cultura CLXXXVI, 741 pp. 59-68 doi: 10.3989/arbor.2010.741n1006

Viñuela Sánchez, E. (2013). El videoclip del siglo XXI: el consumo musical de la televisión e internet. Oviedo: Universidad de Oviedo.

Vernallis, C. (2013). Unruly Media: YouTube, Music Video, and the New Digital Cinema. Oxford Scholarship Online. 10.1093/acprof:oso/9780199766994.001.0001

Voces Fernández, J. (2012). La estructura videoclíptica y su inserción en el cine actual: el caso de El gran Lebowski (Joel Coen, 1998). Salamanca: Universidad de Salamanca.

\section{Videografía:}

Joel Gallen (2001). No es otra estúpida película americana (Not another teen movie) http://gnula.biz/no-es-otra-estupida-pelicula-americana.html

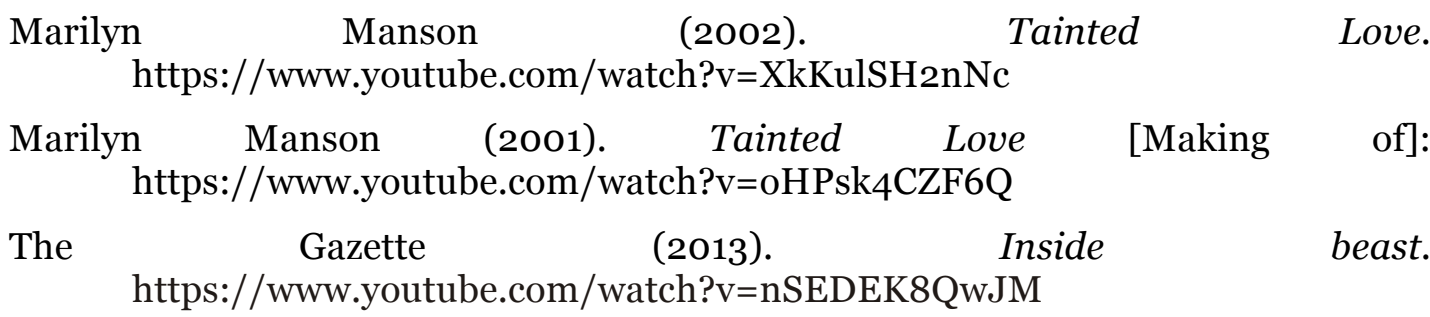

Cómo citar: Vegas Molina, F. (2015). "Cine, videoclip americano y videoclip japonés: la dirección de arte como hilo conductor. El caso de Not Another Teen Movie”. Fotocinema. Revista científica de cine y fotografía, 11, pp. 235260. Disponible: http://www.revistafotocinema.com/ 